\title{
EDUKASI PENTINGNYA MANAJEMEN KESEHATAN REPRODUKSI TERNAK POTONG DAN PENYERAHAN BANTUAN SEMBAKO COVID-19 DI KELOMPOK TERNAK SAPI POTONG “KALIMASODO”, KARANGDUKUH, JOGONALAN, KLATEN, JAWA TENGAH
}

\author{
Lalu Unsunnidhal' ${ }^{1,2)}$, Kurniawan Dwi Prihantoko²), Asmarani Kusumawati²) \\ 1)Program Studi Sarjana IImu Keperawatan, STIKES YARSI Mataram, Mataram, Nusa Tenggara Barat, Indonesia \\ ${ }^{2)}$ Departemen Reproduksi dan Obstetrik, Fakultas Kedokteran Hewan, Universitas Gadjah Mada, Sleman, DIY, Indoensia \\ Corresponding author : Asmarani Kusumawati \\ E-mail : uma_vet@ugm.ac.id
}

Diterima 27 Desember 2020, Direvisi 30 Januari 2021, Disetujui 01 Februari 2021

\begin{abstract}
ABSTRAK
Program pengabdian ini ditujukan untuk memfasilitasi peternak kelompok ternak sapi potong "Kalimasodo" untuk meningkatkan tingkat reproduksi ternak sapi potongnya. Para peternak sapi potong di kelompok ternak "Kalimasodo" tingkat reproduksi dari ternak potong dari kelompok ternak "Kalimasodo" sangatlah rendah, hal ini disebabkan banyaknya anakan sapi yang mati sesaat setelah dilahirkan indukannya. Program pengabdian ini dilakukan untuk meningkatkan tingkat reproduksi dari ternak para peternak di kelompok ternak "Kalimasodo". Usaha peningkatan tersebut dilakukan dengan mengadakan edukasi, diskusi tentang pentingnya manajemen kesehatan reproduksi ternak potong dan praktek langsung kelapangan terkait peningkatan performa ternak dan deteksi dini kebuntingan pada ternak. Tahapan pelaksaanaan kegiatan meliputi observasi awal (16 November 2020), edukasi (23 November 2020) dan Praktek Langsung (24 November 2020). Walaupun jumlah anggota peternak tidak maksimal dikumpulkan untuk edukasi dan praktek dikarenakan mengikuti protokol Covid-19, namun antusias dan respon positif dari para peternak menghasilkan berjalannya dengan baik program pengabdian ini.
\end{abstract}

Kata kunci: sapi potong; manajemen kesehatan; reproduksi ternak; kelompok ternak sapi "kalimasodo".

\begin{abstract}
This service program is aimed at facilitating beef cattle breeders "Kalimasodo" to increase the reproduction rate of their beef cattle. The beef cattle breeders in the "Kalimasodo" herd, the reproductive rate of the beef cattle of the "Kalimasodo" herd is very low, this is due to the large number of calves that die shortly after birth of their broodstock. This service program is carried out to increase the reproduction rate of the livestock breeders in the "Kalimasodo" livestock group. Efforts to increase this are carried out by holding education, discussing the importance of management of the reproductive health of beef cattle and direct field practice related to improving livestock performance and early detection of pregnancy in livestock. The stages of carrying out activities include initial observation (16 November 2020), education (23 November 2020) and Direct Practice (24 November 2020). Although the number of farmer members was not maximally collected for education and practice due to following the Covid-19 protocol, the enthusiasm and positive response from the breeders resulted in the running of this service program well.
\end{abstract}

Keywords: beef cows; health management; animal reproduction; "kalimasodo" cattle group.

\section{PENDAHULUAN}

Desa Karangdukuh, Kecamatan Jogonalan, Kabupaten Klaten dulunya merupakan daerah pertanian yang subur, sehingga penduduknya kebanyakan bertani dan beternak. Produksi beras saat itu memang melimpah dari Desa Karangdukuh, sehingga dapat dijadikan sebagai pendapatan utama sebagian besar warganya. Pada 1980-an, masa paceklik mulai muncul, dimana hasil panen tidak dapat mencukupi untuk memenuhi biaya hidup masyarakat. Alhasil, sebagian masyarakat mulai beralih profesi sebagai pengrajin batu bata. Berbeda dengan siklus pertanian, meskipun produksi bata merah mendatangkan uang lebih cepat, namun justru berdampak pada rusaknya lahan pertanian. Hingga saat ini, keberlangsungan usaha produksi bata merah justru mengalami penurunan. Konversi fungsi lahan pertanian tidak mampu memberikan nilai tambah. Lahan tersebut diolah hanya sebagai bahan baku bata 
merah, bukan sebagai penghasil pangan atau pakan ternak sebagaimana fungsinya. Padahal, dari siklus produksi bata merah, hanya sebagian kecil warga yang menjadi pemilik, hampir $50 \%$ warga hanya menjadi penyewa, pekerja paron atau pencetak bata merah (Budisatria, Atmoko, Ngadiyono, \& Ariyanti, 2017).

Akhirnya, peternakan sapi, kambing dan itik dimulai kembali walau pun dilaksanakan secara tradisional dan perorangan. Secara perorangan karena masing-masing kandang dipisahkan sesuai kemampuan peternak dan masih berada di pekarangan. Secara tradisional karena penyediaan pakan masih bergantung pada tanaman sekitar dan limbah ternak masih menyisakan permasalahan bagi petani dan masyarakat sekitar karena menimbulkan pencemaran lingkungan desa (Budisatria, Atmoko, Ngadiyono, \& Ariyanti, 2017), sehingga dibutuhkan kandang kolektif terutama bagi ternak ruminansia agar pelaksanaan manajemen dari peternakan tersebut lebih teratur dan terarah (Mashur, Oktaviana, Kholik, \& Unsunnidhal, 2019).

Dalam menjawab tantangan tersebut, sejak tahun 2015, terbentuklah kelompok ternak sapi "Kalimasodo" yang memiliki tujuan sebagai inisiator agroindustri masyarakat desa karangdukuh menuju visi pengelolaan terpadu peternakan dalam meningkatkan taraf hidup kesejahteraan masyarakatnya. Salah satu usaha dalam mewujudkan hal tersebut, maka didirikanlah kandang sapi terpadu dengan meminjam lahan pesantren Joglo Alit dengan daya tampung mencapai 40 ekor sapi. Keanggotaan kelompok ternak sapi Kandang Kalimasodo hingga saat ini telah mencapai 21 peternak sapi. Namun, tingkat reproduksi dari ternak-ternak sapi tersebut yang sangat rendah dan banyaknya anakan yang mati setelah dilahirkan oleh indukannya menjadi kendala utama dalam mencapai tujuan dan visi dari kelompok ternak sapi potong "Kalimasodo". Tingkat reproduksi dalam usaha peternakan sapi potong sangatlah penting dalam meningkatkan pendapatan atau income bagi para peternak sapi potong, hal ini dikarenakan peningkatan income akan seiring dengan peningkatan jumlah anakan dari ternak-ternak sapi potong tersebut. Disisi lain, peningkatan income sangat dibutuhkan dalam peningkatan taraf hidup kesejahteraan masyarakat (Unsunnidhal \& Suryawati, Penguatan Ekonomi Masyarakat Pasca Bencana Gempa melalui Pendampingan Pembuatan Usaha Rumahan di Pemenang Barat, 2020); (Unsunnidhal \& Suryawati, Analisis Risiko Usaha Ternak di Dusun Koloh Brora dan Pengenalan Upaya
Mitigasi Risiko melalui Diversifikasi Usaha, 2020).

Dalam upaya peningkatan tingkat reproduksi dari ternak sapi potong dibutuhkan pengelolaan atau manajemen kesehatan reproduksi yang baik dari para peternak sapi potong pada kandang kelompok "Kalimasodo". Manajemen kesehatan reproduksi ternak merupakan proses perencanaan, pengorganisasian, pelaksanaan dan pengendalian faktor-faktor reproduksi melalui optimalisasi sumber daya yang tersedia agar produktivitas ternak dapat maksimal, Kesehatan ternak dapat dioptimalkan dan kualitas reproduksi ternak dapat ditingkatkan sesuai dengan standar yang diinginkan (Mashur, Oktaviana, Kholik, \& Unsunnidhal, 2019).

paling berpengaruh dalam buruknya manajemen Kesehatan reproduksi di kandang kelompok "Kalimasodo" telah dilaksanakan observasi awal. Observasi awal dilaksanakan untuk mengetahui faktor penyebab kurang optimalnya suatu kegiatan usaha di masyarakat (Unsunnidhal \& Suryawati, Penguatan Ekonomi Masyarakat Pasca Bencana Gempa melalui Pendampingan Pembuatan Usaha Rumahan di Pemenang Barat, 2020). Berdasarkan observasi awal tersebut telah diketahui bahwa rendahnya tingkat Pendidikan dan pemahaman peternak menjadi faktor utama yang perlu diperhatikan. Pemahaman yang baik akan memberikan behaviour yang baik dalam manajemen pemeliharaan sapi potong. Misalnya deteksi estrus yang tepat, deteksi gangguan reproduksi yang cepat dan akurat, pemberian pakan yang sesuai, kandang yang bersih dan sehat mampu mencegah berbagai masalah gangguan reproduksi. Selain itu, mengingat para peternak sapi potong kandang kelompok "Kalimasodo" juga terkena imbas negatif terkait perekonomian dari pandemik covid-19 maka dibutuhkan pemberian bantuan baik itu berupa sembako dan uang tunai untuk meningkatkan antusias para peternak sapi potong dalam menyerap ilmu yang diberikan dan memenuhi kebutuhan pokok sehari-hari.

Berdasarkan uraian-uraian tersebut, sehingga dilaksanakannya pengabdian yang berjudul edukasi pentingnya manajemen manajemen kesehatan reproduksi ternak potong dan penyerahan bantuan sembako Covid-19 di Kelompok Ternak Sapi Potong "Kalimasodo", Karangdukuh, Jogonalan, Klaten, Jawa Tengah.

\section{METODE \\ Metode kegiatan pengabdian masyarakat yang telah dilaksanakan adalah}


pemberian edukasi, diskusi (sharing informasi) dan praktek langsung. Jumlah peternak dari kelompok ternak sapi potong "Kalimasodo" yang hadir dalam pengabdian masyarakat ini hanya 25 peternak, hal ini dikarenakan mengikuti protokol Covid-19 yang tidak diperbolehkan mengumpulkan masa dalam jumlah yang banyak. Tema pemberian edukasi, diskusi (sharing informasi) dan praktek langsung yang telah dilaksanakan di kelompok ternak sapi potong "Kalimasodo", Karangdukuh, Jogonalan, Klaten, Jawa Tengah adalah edukasi pentingnya manajemen kesehatan reproduksi ternak potong, selain itu telah dilaksanakan juga penyerahan bantuan sembako Covid-19 kepada para peternak di kelompok ternak sapi potong "Kalimasodo", dengan hasil yang telah dicapai dari kegiatan pengabdian masyarakat ini adalah peningkatan pengetahuan para peternak dari kelompok ternak sapi potong "kalimasodo" terkait edukasi pentingnya manajemen kesehatan reproduksi ternak potong.

$$
\text { Pengabdian masyarakat ini }
$$

dilaksanakan selama dua hari, yaitu pada hari senin, tanggal 23 November 2020 untuk pelaksanaan pemberian edukasi dan penyerahan sembako, kemudian pada hari selasa, tanggal 24 November 2020 untuk praktek langsung pada ternak sapi potong. Pengabdian masyarakat ini dilaksanakan di kandang kelompok ternak sapi potong "Kalimasodo", Karangdukuh, Jogonalan, Klaten, Jawa Tengah. Namun, sebelum pelaksanaan kegiatan pengabdian masyarakat ini, telah dilaksanakan observasi awal tepatnya $\mathrm{H}-7$ sebelum hari pelaksanaan kegiatan. Observasi awal dilaksanakan untuk mengetahui faktor penyebab kurang optimalnya suatu kegiatan usaha di masyarakat (Unsunnidhal \& Suryawati, Penguatan Ekonomi Masyarakat Pasca Bencana Gempa melalui Pendampingan Pembuatan Usaha Rumahan di Pemenang Barat, 2020).

\section{HASIL DAN PEMBAHASAN}

Program pengabdian ini dilaksanakan sesuai dengan jadwal yang telah direncanakan yaitu tanggal 23 November 2020 untuk pelaksanaan edukasi berikut diskusi (sharing informasi) terkait pentingnya manajemen kesehatan reproduksi ternak potong. Kemudian di hari yang sama pula dilaksanakan penyerahan bantuan sembako dalam rangkan membantu peternak melewati masa-masa sulit dikarenakan pandemik Covid-19. Kemudian, hari selanjutnya tepatnya pada tanggal 24 November 2020 dilaksanakan praktek langsung manajemen kesehatan reproduksi di kandang kelompok sapi potong "Kalimasodo".
Sebelumnya telah dilaksanakan observasi awal yaitu pada tanggal 16 November 2020 untuk diskusi, survey lapangan pada kandang kelompok para peternak dan studi awal dalam kaitan menganalisis kebutuhan dan permasalahan yang dihadapi oleh kelompok ternak sapi potong "Kalimasodo" dan observasi awal tersebut telah tersaji berbentuk dokumentasi seperti pada Gambar 1 dan Gambar 2.

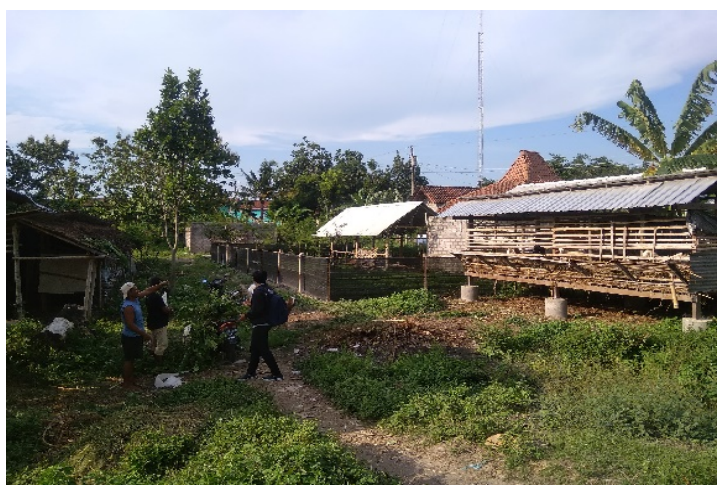

Gambar 1. Survei Kandang Kelompok

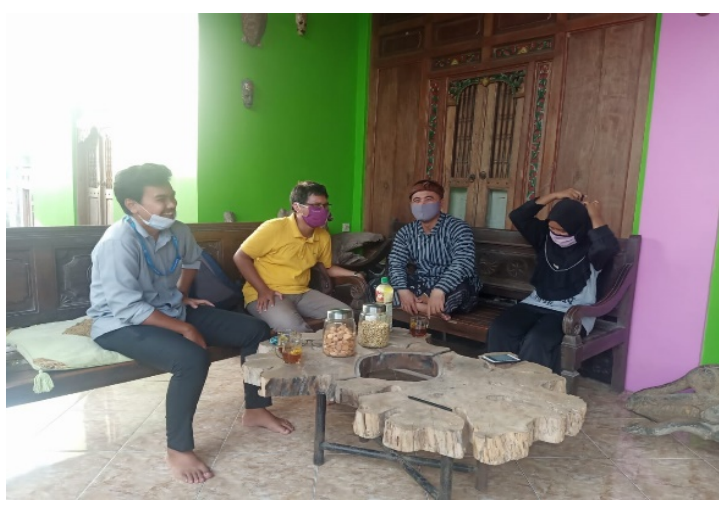

Gambar 2. Diskusi dan Studi Awal pada Kelompok Ternak

Pada hari pertama kegiatan yaitu pada tanggal 23 November 2020, acara pertama yang dilaksanakan adalah edukasi dan diskusi (sharing informasi) terkait pentingnya manajemen kesehatan reproduksi ternak potong yang diberikan oleh Dr. drh. Irkham Widiyono. Materi yang diberikan meliputi tandatanda birahi, mendeteksi gangguan reproduksi dan pemahaman mengenai manajemen reproduksi sehingga dapat meningkatkan performa reproduksi ternak. Para peternak juga memberikan respon positif terhadap materi yang diberikan. Hal ini terlihat dari para peternak yang sangat antusias untuk bertanya dan berdiskusi mengenai masalah-masalah yang sering dihadapi di lapangan pada sesi diskusi. Hal tersebut terdokumentasi sebagaimana pada Gambar 3 dan Gambar 4. 


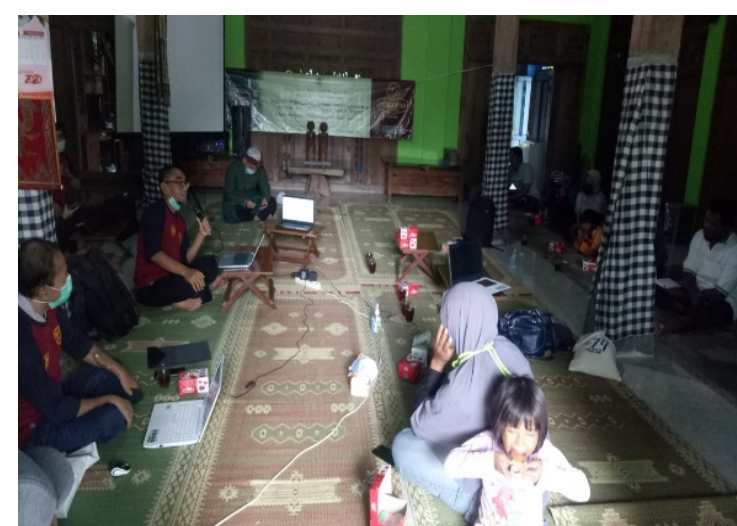

Gambar 3. Pemberian materi edukasi manajemen kesehatan reproduksi

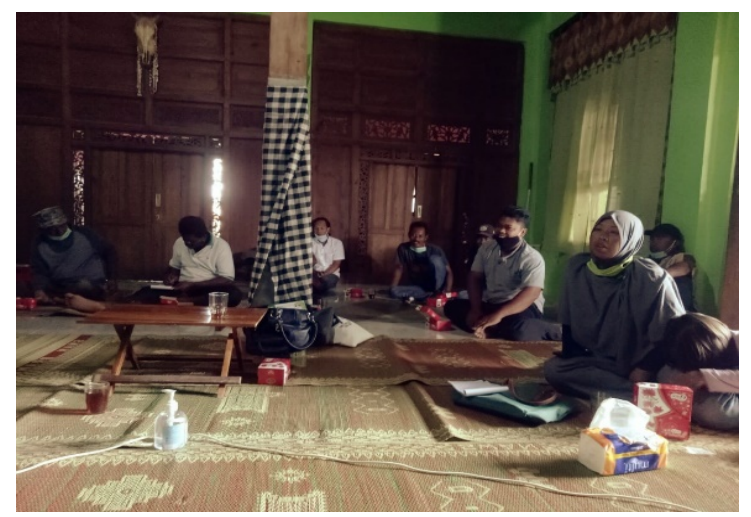

Gambar 4. Peserta antusias bertanya pada sesi diskusi

Kegiatan selanjutnya setelah edukasi dan diskusi adalah penyerahan bantuan sembako kepada para peternak sapi potong "Kalimasodo". Hal ini mengingat suasana pembatasan yang dikarenakan pandemic Covid-19 sehingga pelaksana kegiatan berharap bantuan sembako ini dapat meringankan beban keluarga yang bertambah karena pembatasan kegiatan untuk mencari nafkah dikarenakan pandemik Covid-19. Kegiatan ini terdokumentasi pada Gambar 5 dan Gambar 6.

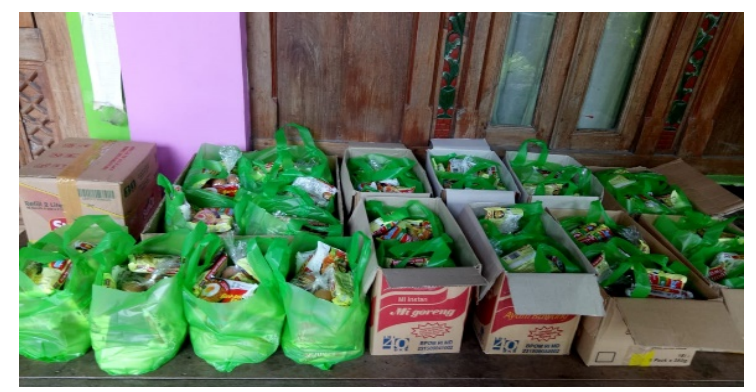

Gambar 5. Paket Sembako yang akan diserahkan

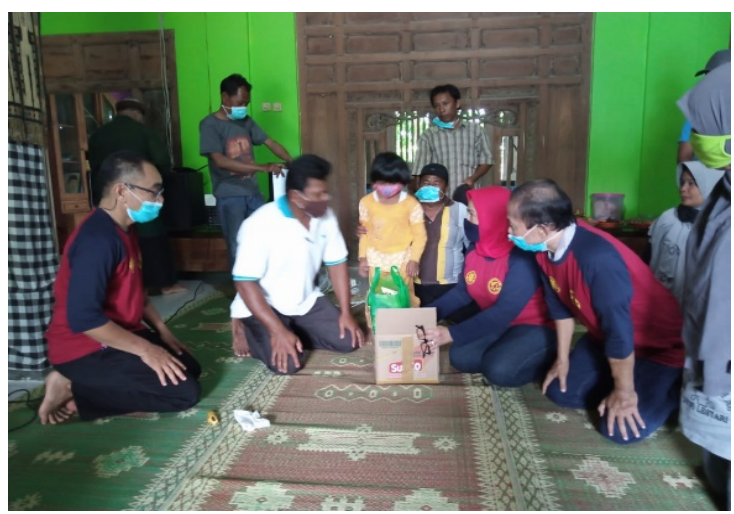

Gambar 6. Penyerahan Paket Sembako kepada Ketua Kelompok Ternak Sapi Potong "Kalimasodo"

Selama kegiatan berlangsung, kendala utama adalah kurang maksimalnya peserta peternak sapi potong kelompok ternak "kalimasodo" yang diundang. Hal ini dikarenakan protokol pandemik Covid-19 yang harus dilaksanakan. Selain itu, terganggu nya komunikasi karena kewajiban pemakaian masker mengikuti protokol Covid-19, berkat antusias peserta acara pengabdian, acara pengabdian hari pertama dapat diselesaikan dengan baik.

Hari berikutnya tepatnya tanggal 24 November 2020, dilaksanakan praktek langsung terkait manajemen kesehatan reproduksi ternak potong di kandang kelompok "Kalimasodo". Kegiatan ini memfasilitasi para peternak untuk dapat melihat teknis langsung pemberian vitamin dan palpasi rektal. Sehingga para peternak dapat secara mandiri melaksanakan pemberian vitamin untuk meningkatkan performa ternaknya dan palpasi rektal untuk mengetahui kondisi kebuntingan pada ternak, dengan ternak yang memiliki tanda-tanda ternak lebih tenang, tidak suka dekat dengan pejantan dan nafsu makan agak meningkat

(Balai_Pengkajian_Teknologi_Pertanian_(BPT P)_Jawa_Barat, 2010). Hal ini sangat penting untuk segera memberikan obat-obatan dan Tindakan selanjutnya dalam mempersiapkan kebuntingan pada ternak. Sebagaimana sesuai arahan pada edukasi yang diberikan sebelumnya. Beberapa persiapan yang perlu dilakukan apabila sapi memperlihatkan gejalagejala akan melahirkan adalah pembersihan kandang untuk memudahkan pergerakkan induk sebelum atau pada saat proses melahirhkan, lantai kandang diberi alas, berupa jerami padi kering sebagai alas agar cairan yang keluar selama proses kelahiran dapat terserap dengan cepat dan disediakan obatobatan untuk mengantisipasi keadaan darurat (Balai_Pengkajian_Teknologi_Pertanian_(BPT 
P)_Jawa_Barat, 2010). Rangkaian kegiatan tersebut tersaji pada Gambar 7.

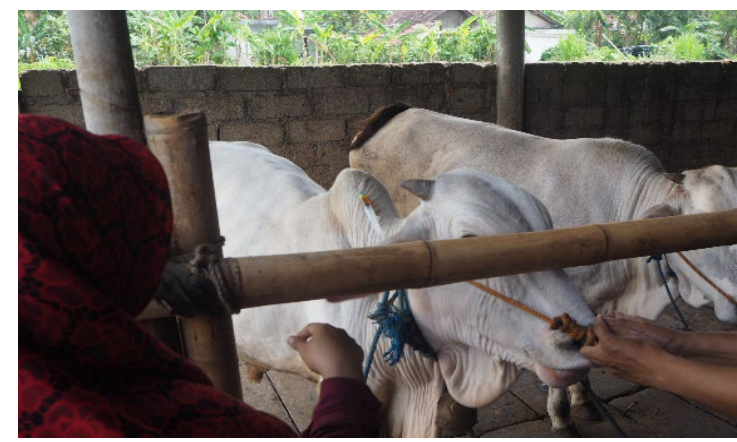

Gambar 7. Praktek langsung terkait manajemen kesehatan reproduksi ternak potong di kandang kelompok "Kalimasodo".

Beberapa peserta mengutarakan kekhawatirannya terkait dosis vitamin yang diberikan. Tim pengabdian memfasilitasi dengan memberikan arahan terkait dosis vitamin yang diberikan kepada ternakternaknya. Perihal masih bingungnya para peternak dengan teknis palpasi rektal, tim penyluhan memberikan arahan untuk dalam praktek nantinya didampingi oleh mantri ternak yang ada di Desa.

\section{SIMPULAN DAN SARAN}

Kegiatan pengabdian edukasi pentingnya manajemen kesehatan reproduksi ternak potong telah dilaksanakan dan dapat berjalan dengan lancar. Dengan adanya pengabdian ini diharapkan para peternak sapi potong kelompok ternak sapi potong "Kalimasodo", Karangdukuh, Jogonalan, Klaten, Jawa Tengah dapat meningkatkan kualitas kesehatannya dengan menerapkan perilaku sehat dan dapat meningkatkan produktivitas ternak sapi potongnya. Saran untuk meningkatkan produksi ternaknya dapat melalui koordinasi internal. Koordinasi internal yang dimaksud dalam berdiskusi dengan mantri ternak yang terdapat di desanya.

\section{DAFTAR RUJUKAN}

Balai_Pengkajian_Teknologi_Pertanian_(BPT P)_Jawa_Barat. (2010). Folder Manajemen Sapi Potong - BPTP Jawa Barat. Retrieved from Folder Manajemen Sapi Potong - BPTP Jawa Barat:

http://jabar.litbang.pertanian.go.id/imag es/dokumen/leaflet/Manajemen\%20Re produksi\%20Sapi\%20Potong.pdf

Budisatria, I., Atmoko, B., Ngadiyono, N., \& Ariyanti, F. (2017). Breding Center: Teknologi Tepat Guna untuk Meningkatkan Panen Cempe pada
Induk Kambing di Tingkat Peternak Rakyat. Prosiding in Seminar Nasional Peternakan 3 Tahun 2017 (pp. 328-38). Makasar: Fakultas Peternakan, Universitas Hasanudin.

Mashur, Oktaviana, D., Kholik, \& Unsunnidhal, L. (2019). Implementation of Health Management of a Beef Catle Feed and the Collective Cage Based Smallholder Farming in Lombok Island. Proceedings of The 2nd International Conference on Bioscience, Biotechnology and Biometrics (pp. 1-5 (DOI: 10.1063/1.5141305)). Lombok: AIP Publishing.

Unsunnidhal, L. (2020). Bab 7 Aspek Prebiotik dan Probiotik: Evaluasi pada Keamanan dan Manfaat Kesehatan. In Pattola, A. Nur, T. A.-G. Atmadja, A. E. Yunianto, Rasmaniar, I. Marzuki, . . . A. V. Purba, Gizi, Kesehatan dan Penyakit (pp. 95-108). Medan: Yayasan Kita Menulis.

Unsunnidhal, L., \& Suryawati, B. N. (2020). Analisis Risiko Usaha Ternak di Dusun Koloh Brora dan Pengenalan Upaya Mitigasi Risiko melalui Diversifikasi Usaha. SASAMBO: Jurnal Abdimas (Journal of Community Service), 64-69 (DOI: 10.36312/sasambo.v2i2.131).

Unsunnidhal, L., \& Suryawati, B. N. (2020). Penguatan Ekonomi Masyarakat Pasca Bencana Gempa melalui Pendampingan Pembuatan Usaha Rumahan di Pemenang Barat. Selaparang. Jurnal Pengabdian Masyarakat Berkemajuan, 166-169 (DOI: 10.31764jpmb.v3i2.2016. 